\title{
Can Fishing Pressure Invert the Outcome of Interspecific Competition? The Case of the Thiof and of the Octopus Along the Senegalese Coast
}

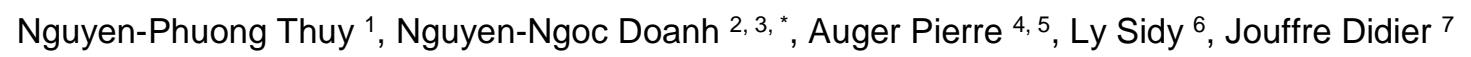

1 Hanoi Univ Sci \& Technol, Sch Appl Math \& Informat, 1 Dai Co Viet St, Hanoi, Vietnam.

2 Thuyloi Univ, Fac Comp Sci \& Engn, 175 Tay Son St, Hanoi, Vietnam.

3 IRD UPMC Paris 6, UMI UMMISCO 209, 32 Ave Henri Varagnat, F-93143 Bondy, France.

4 Sorbonne Univ, Univ Paris 06, IRD, UMI 209, Bondy, France.

5 Univ Cheick Anta Diop, UMI IRD UMMISCO UCAD 209, Dakar, Senegal.

6 Univ Cheikh Anta Diop, FASEG LMDAN, Dakar, Senegal.

7 IRD, LABEP AO IRD IFAN, UMR MARBEC 248, BP 1386, Dakar, Senegal.

*Corresponding author : Doanh Nguyen-Ngoc, email address : doanhbondy@gmail.com

\begin{abstract}
:
We present a mathematical model of two competing marine species that are harvested. We consider three models according to different levels of complexity, without and with species refuge and densityindependent and density-dependent species movement between fishing area and refuge. We particularly study the effects of the fishing pressure on the outcome of the competition. We focus on conditions that allow an inferior competitor to invade as a result of fishing pressure. The model is discussed in relationship to the case of the thiof and the octopus along the Atlantic West African coast. At the origin, the thiof was abundant and the octopus scarce in that region. Since, the fishing pressure has strongly increased in some fishing areas leading to the depletion of the thiof and the invasion of its competitor, the octopus.
\end{abstract}

Keywords : Competition, Refuge, Density-dependent migration, Density-independent migration, Fishing pressure 


\section{Introduction}

The North western African coast lying from the Saharan bank to the Guinean shelf is known to be one of the most productive marine area in world due to hydro-climatic conditions that induce the presence of a strong regional upwelling system $[4,15,30]$. In link with this high level of biological productivity, this marine area is subjected to a very ancient fishery exploitation [7], with a fishing pressure that began to reach very high rate during the last past half century $[1,5,14,29]$ and is still increasing from the sixties until now [14]. This evolution of the fishing pressure led ecological changes and important evolutions within the marine communities, in particular within the exploited macrofauna (fishes, shellfish and cephalopods) [14]. Among the most striking changes, two facts were observed and 
widely documented. The first one concerns the population boom of the octopus (Octopus vulgaris) in Northwest Africa, which occurred from the North area (Sahara, Mauritania) from the sixties $[8,11,21,28]$ and propagated southward to reach Senegal from the years eighty $[10,11,16]$. The second change concerns a drastic and generalised depletion of the demersal fishes abundances as a consequence of fishing effect [14]. This generalised decrease of fish abundances lies since more than fifty year and concerns more or less almost all demersal fish populations of the area from north to south, but especially those of Sparidae and of Serranidae species who matter among the most valuable and fishery targeted species. Several authors made the link between these two observations [5,9], in particular in studies having attempting to describe and to understand the wide demographic explosion of octopus at the west Africa regional scale, a species reported to be already present in the whole area at the beginning of the century but at very low concentrations except punctually and in geographically very limited spots $[8,20,28]$. These authors so emitted the hypothesis as the emergence of octopuses high concentrations, in the North first and at the scale of the whole region then, had been made possible by the preliminary depletion of most of the demersal fishes $[5,6,9]$, considered as their main predators and competitors for food supply and space $[11,13,20]$. In previous works this hypothesis was thus established as direct interpretation of the co-evolutions observed between these two groups as well as the knowledge on their biology and their ecology. To our knowledge this hypothesis was never the object of any attempt to test it nor of any exploratory specific analysis of mechanisms possibly in game. This is the objective the present study, that suggests to do this using a modelling approach, with the construction of a theoretical competition model envisaged more specifically to reproduce and analyse the interspecific relations and the joint dynamics of the Senegalese populations of octopus and of a grooper called thiof (Epinephelus aenus), one of the most common and emblematic serranidae of th area, over the period from the 1970s to our days. The choice of the thiof (rather than another demersal fish) and of the Senegalese area are justified because in Senegal, the thiof was very abundant in the 70s as the octopus was almost absent or rather scarce. Octopus demographic explosion in Senegal is reported to have began in the 80th $[10,11,16]$ as well as its fishing exploitation. The thiof represents one of the most ancient and emblematic fishing ressource of Senegal as well as the one that registered the most drastic and continuous decrease in abundance during the last half century, a decrease frequently highlighted as the most convincing example of overfishing effect in the area $[22,23,25,31]$. This species is also very well known by Senegalese people because considered as one of the best fish to use in the national dish (Tieboudienne), even if it is nowadays frequently replaced by less expensive fishes. The thiof and the octopus are competitive species feeding from some common resources and big thiof specimen are also a potential predators octopuses. The case of the thiof and the octopus in Senegal lead us to consider a mathematical model of two marine species competing for a common resource and that are harvested by the same fishing fleet. We assume that in absence of fishing, species 1 (thiof) would be a superior competitor and species 2 (octopus) an inferior one. This means that 
without fishing, it is assumed that species 1 would outcompete species 2 . Throught this model we want to explore the potential effects of fishing both species on the outcome of interspecific competition. We want to address the following questions:

- Can fishing provoke extinction of a superior competitor and induce invasion of an inferior one?

- Can the demograhic explosion of octopus in west Africa be explained by an indirect effect of high fishing pressure that have modified the outcome of interspecific competition between octopus and some of their demersal fish competitors?

- Which consequence can we draw from this in terms of stock assessment and fisheries management of these resources in the area?

\section{Model}

We consider a model consists in two competing species in a context of fishing dynamics. We assume that two species are fished by a constant fishing effort. Considering that the two species are territorial and can use refuge, we envisaged the two options for the modeling: the case without refuge (model 1) and the case with refuge (model 2).

2.1 Model 1: the case without refuge

We first consider the case without refuge. In this case, the model reads as follows.

$$
\left\{\begin{array}{l}
\frac{d n_{1}}{d t}=r_{1} n_{1}\left(1-\frac{n_{1}}{K_{1}}-a_{12} \frac{n_{2}}{K_{1}}\right)-q_{1} n_{1} E \\
\frac{d n_{2}}{d t}=r_{2} n_{2}\left(1-\frac{n_{2}}{K_{2}}-a_{21} \frac{n_{1}}{K_{2}}\right)-q_{2} n_{2} E
\end{array}\right.
$$

where $n_{i}$ is the densities of species $i, i \in\{1,2\} . r_{i}$ and $K_{i}$ are the growth rate and the carrying capacity of the species $i, i \in\{1,2\}$. The parameter $E$ is a constant fishing effort. The parameter $q_{i}$ represents the capture rate of the fishing on the species $i, i \in\{1,2\}$. Throughout the paper, we are interested in the asymmetric competition meaning that species 1 is the superior competitor and species 2 is the inferior competitor. A straightforward calculation leads to the following condition for the asymmetric competition:

$$
\frac{a_{12} K_{2}}{K_{1}}<1<\frac{a_{21} K_{1}}{K_{2}}
$$


There are at most four non-negative equilibria which are $P_{0}(0,0), P_{1}\left(\left(r_{1}-q_{1} E\right) K_{1} / r_{1}, 0\right)$ (if $r_{1}-q_{1} E>0$ ), $P_{2}\left(0,\left(r_{2}-q_{2} E\right) K_{2} / r_{2}\right)$ (if $\left.r_{1}-q_{1} E>0\right)$ and $P_{*}\left(n_{1}^{*}, n_{2}^{*}\right)$ provided one of the following two conditions holds:

$$
(i): \frac{a_{12} K_{2}}{K_{1}} \times \frac{r_{2}-q_{2} E}{r_{2}}<\frac{r_{1}-q_{1} E}{r_{1}}<\frac{K_{2}}{a_{21} K_{1}} \times \frac{r_{2}-q_{2} E}{r_{2}}
$$

or

$$
\text { (ii) : } \frac{K_{2}}{a_{21} K_{1}} \times \frac{r_{2}-q_{2} E}{r_{2}}<\frac{r_{1}-q_{1} E}{r_{1}}<\frac{a_{12} K_{2}}{K_{1}} \times \frac{r_{2}-q_{2} E}{r_{2}}
$$

Denoting

$$
O_{1}=q_{1} E-r_{1} ; O_{2}=q_{2} E-r_{2}, I_{1}=\frac{O_{2}}{r_{2}} \times \frac{a_{12} K_{2}}{K_{1}}-\frac{O_{1}}{r_{1}} ; I_{2}=\frac{O_{1}}{r_{1}}-\frac{O_{2}}{r_{2}} \times \frac{K_{2}}{K_{1} a_{21}}
$$

The condition $O_{i}>0$ means that species $i$ is over exploited. While the condition $I_{i}>0$ is related to the case where species $i$ can invade when rare, $i \in\{1,2\}$. It is obvious that if species is over exploited then it gets extinct. For instance, if $O_{1}>0$ and $O_{2}<0$, it means that due to overfishing, the superior competitor is going extinct while the inferior competitor which is not overexploited will survive and tend to some carrying capacity. Now we consider the case where both species are not over exploited. In this case, model 1 is the same as the classical Lotka-Volterra competition model [24]. The outcomes of model 1 are therefore the following: (i) the superior competitor wins globally; $(i i)$ the inferior wins globally; (iii) species wins depending on initial conditions; or $(i v)$ the two species coexists. We are interested in the case where the inferior competitor wins globally- case $(i i)$. This case is valid if $O_{1}, O_{2}, I_{1}<0$ and $I_{2}>0$. These inequalities hold provided $K_{2}>K_{1}$ which is in agreement with the case of thiof and octopus. The environment carrying capacity of the inferior competitor -octopus $\left(K_{2}\right)$ is much large than the one of the superior competitor-thiof $\left(K_{1}\right)$. Figure 1 shows a phase portrait corresponding to the case.

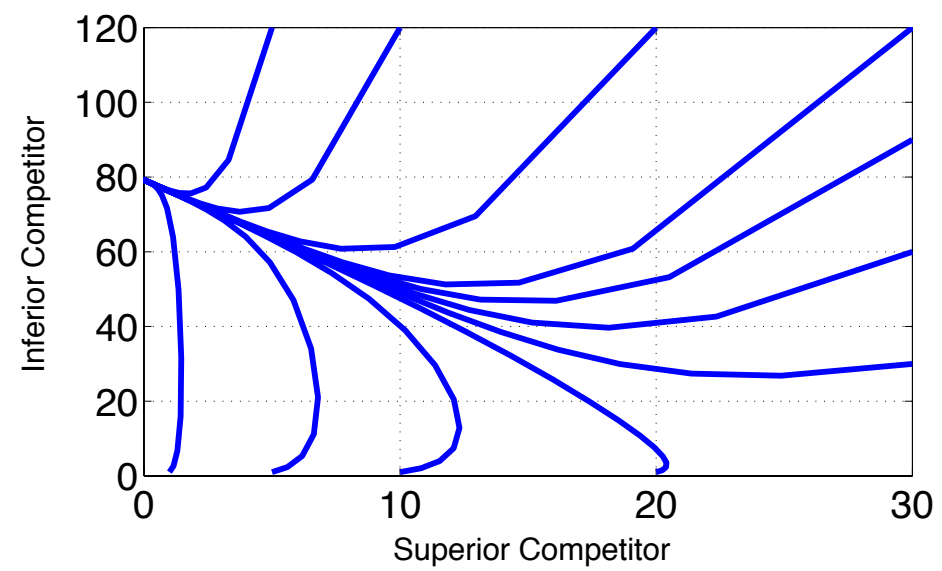

Fig. 1 Example with the inferior competitor wins globally in model 1. Parameters are chosen as follows $r_{1}=0.7 ; r_{2}=1.3 ; K_{1}=100 ; K_{2}=$ $100 ; a_{12}=0.8 ; a_{21}=2.2 ; q_{1}=0.6 ; q_{2}=0.3 ; E=0.9$. 
2.2 Model 2: the case with refuge and density independent migration

It is the fact that both species are territorial at least during some stages of their life. Observations have shown that the grouper and the octopus spend part of their time at some stages in their refuges $[12,13,19]$. Therefore, in this part we considered a model with two patches, a refuge and a patch where they need to come to find food. We suppose that there is no food in the refuge and thus individuals cannot survive and die. However, in the refuge, individuals are protected from fishing. However, individuals cannot stay in the refuge in the long term and they need to come back to the common patch to find and compete for food $[12,17]$. We assume that for both species, the migration is density independent and is faster than the growth and mortality in the refuge and fishing in the common patch. Regarding the density independence it is a statement put in the model 2, but we don't know if it realistic or not. May be the inferior competitor (octopus) have a migration rate depending on the density of the superior competitor (grouper). So we will consider the alternative hypothesis in a following step (see model 3). Regarding the speed of the migration we can assume the hypothesis considering the feeding behavior of the two species $[12,17]$ and because in the present case for both species the refuge area is composed of several individual refuges distributed inside the large and common fishing area so that each species can leave their refuge at any time and reach the fishing zone almost instantaneously (with migration time non significant compared to time spent in the refuges and the common fishing area). In general, the dynamics of such a model is given by

$$
\left\{\begin{array}{l}
\frac{d n_{1 F}}{d \tau}=\left(k n_{1 R}-\bar{k} n_{1 F}\right)+\varepsilon r_{1} n_{1 F}\left(1-\frac{n_{1 F}}{K_{1}}-a_{12} \frac{n_{2 F}}{K_{1}}\right)-\varepsilon q_{1} n_{1 F} E \\
\frac{d n_{1 R}}{d \tau}=\left(\bar{k} n_{1 F}-k n_{1 R}\right)-\varepsilon d_{1} n_{1 R} \\
\frac{d n_{2 F}}{d \tau}=\left(m n_{2 R}-\bar{m} n_{2 F}\right)+\varepsilon r_{2} n_{2 F}\left(1-\frac{n_{2 F}}{K_{2}}-a_{21} \frac{n_{1 F}}{K_{2}}\right)-\varepsilon q_{2} n_{2 F} E \\
\frac{d n_{2 R}}{d \tau}=\left(\bar{m} n_{2 F}-m n_{2 R}\right)-\varepsilon d_{2} n_{2 R}
\end{array}\right.
$$

where $n_{i F}$ and $n_{i R}$ are the densities of species $i, i \in\{1,2\}$, in the fishing patch and in the refuge, respectively. Like in the previous model, $r_{i}$ and $K_{i}$ are the growth rate and the carrying capacity of the species $i$ in the fishing patch. 
$d_{i}$ is the natural death rate of species $i$ in the refuge, $i \in\{1,2\}$. The parameter $E$ is a constant fishing effort. The parameter $q_{i}$ represents the capture rate of the fishing on the species $i$. In addition, we suppose that $k$ and $m$ are the emigration rates from the refuge to the fishing patch of species 1 and 2. The parameter $\bar{k}$ and $\bar{m}$ is the emigration rate from the fishing patch to the refuge patch of species 1 and 2 . The parameter $\varepsilon$ represents the ratio between two time scales $t=\varepsilon \tau$. Keeping in mind that we are still interested in the asymmetric competition. Therefore we use again the condition 2.2.

The model is similar to the one presented in [26]. We use aggregation method to transform this model into a reduced system with two ordinary differential equations governing the dynamics of the global variables: the total density of species $1, n_{1}(t)=n_{1 F}(t)+n_{1 R}(t)$, and the total density of species $2, n_{2}(t)=n_{2 F}(t)+n_{2 R}(t)$. Both are adequate candidates to global variables because they are constants of motion of the migration process, i.e., they keep constant at the fast time scale. If we forget the competitive interactions, global densities will not change but the distribution of each species between the two patches will evolve and tend towards certain equilibrium proportions. To calculate them let us suppose fixed values of $n_{1}$ and $n_{2}$ and find the equilibria of the fast part of system 2.3. We obtain for species 1

$$
n_{1 F}=\frac{k}{k+\bar{k}} n_{1}=v_{1}^{*} n_{1} \text { and } n_{1 R}=\frac{\bar{k}}{k+\bar{k}} n_{1}=v_{2}^{*} n_{1}
$$

and for species 2

$$
n_{2 F}=\frac{m}{m+\bar{m}} n_{1}=u_{1}^{*} n_{1} \text { and } n_{2 R}=\frac{\bar{m}}{m+\bar{m}} n_{1}=u_{2}^{*} n_{1}
$$

where constants $v_{1}^{*}$ and $v_{2}^{*}$ represent the fast equilibrium proportions of species 1 on each patch while the constants $u_{1}^{*}$ and $u_{2}^{*}$ represent the fast equilibrium proportions of species 2 on each patch. It is immediate to prove that these equilibria are stable for fast dynamics.

Now, coming back to the complete model (2.3), we can write a system for the two global variables just by adding up the corresponding equations and substituting the former state variables by the fast equilibria (2.4) and (2.5) as follows:

$$
n_{1 F}=v_{1}^{*} n_{1}, n_{1 R}=v_{2}^{*} n_{1}, n_{2 F}=u_{1}^{*} n_{2} \text { and } n_{2 R}=u_{2}^{*} n_{2}
$$

Obtaining the following aggregated system at the slow time scale:

$$
\left\{\begin{array}{l}
\frac{d n_{1}}{d t}=n_{1}\left[\left(r_{1} v_{1}^{*}-q_{1} v_{1}^{*} E-d_{1} v_{2}^{*}\right)-\frac{r_{1} v_{1}^{* 2}}{K_{1}} n_{1}-\frac{r_{1} a_{12} v_{1}^{*} u_{1}^{*}}{K_{1}} n_{2}\right] \\
\frac{d n_{2}}{d t}=n_{2}\left[\left(r_{2} u_{1}^{*}-q_{2} u_{1}^{*} E-d_{2} u_{2}^{*}\right)-\frac{r_{2} u_{1}^{* 2}}{K_{2}} n_{2}-\frac{r_{2} a_{21} u_{1}^{*} v_{1}^{*}}{K_{2}} n_{1}\right]
\end{array}\right.
$$


According to aggregation methods [2,3], we can study the dynamics of the complete system (2.3) by carrying out the study of the aggregated model (2.6).

There are at most four non-negative equilibria which are $\bar{P}_{0}(0,0), \bar{P}_{1}\left(\left(r_{1} v_{1}^{*}-d_{1} v_{2}^{*}-q_{1} v_{1}^{*} E\right) K_{1} / r_{1}\left(v_{1}^{*}\right)^{2}, 0\right)$ (if $\left.\left.r_{1} v_{1}^{*}-d_{1} v_{2}^{*}-q_{1} v_{1}^{*} E\right)>0\right), \bar{P}_{2}\left(0,\left(r_{2} u_{1}^{*}-d_{1} u_{2}^{*}-q_{2} u_{1}^{*} E\right) K_{2} / r_{2}\left(u_{1}^{*}\right)^{2}\right)$ (if $\left.\left(r_{2} u_{1}^{*}-d_{1} u_{2}^{*}-q_{2} u_{1}^{*} E\right)>0\right)$ and $\bar{P}_{*}\left(\hat{n}_{1}, \hat{n}_{2}\right)$ provided one of the following two conditions holds:

$$
\text { (a) }: \frac{a_{12} K_{2}}{K_{1}} \times \frac{r_{2} u_{1}^{*}-d_{1} u_{2}^{*}-q_{2} u_{1}^{*} E}{r_{2} u_{1}^{*}}<\frac{r_{1} v_{1}^{*}-d_{1} v_{2}^{*}-q_{1} v_{1}^{*} E}{r_{1} v_{1}^{*}}<\frac{K_{2}}{a_{21} K_{1}} \times \frac{r_{2} u_{1}^{*}-d_{1} u_{2}^{*}-q_{2} u_{1}^{*} E}{r_{2} u_{1}^{*}}
$$

or

$$
\text { (b) }: \frac{K_{2}}{a_{21} K_{1}} \times \frac{r_{2} u_{1}^{*}-d_{1} u_{2}^{*}-q_{2} u_{1}^{*} E}{r_{2} u_{1}^{*}}<\frac{r_{1} v_{1}^{*}-d_{1} v_{2}^{*}-q_{1} v_{1}^{*} E}{r_{1} v_{1}^{*}}<\frac{a_{12} K_{2}}{K_{1}} \times \frac{r_{2} u_{1}^{*}-d_{1} u_{2}^{*}-q_{2} u_{1}^{*} E}{r_{2} u_{1}^{*}}
$$

Denoting

$$
\begin{gathered}
\bar{O}_{1}=-r_{1} v_{1}^{*}+d_{1} v_{2}^{*}+q_{1} v_{1}^{*} E ; \bar{O}_{2}=-r_{2} u_{1}^{*}+d_{1} u_{2}^{*}+q_{2} u_{1}^{*} E \\
\bar{I}_{1}=\frac{\bar{O}_{2}}{r_{2} u_{1}^{*}} \times \frac{a_{12} K_{2}}{K_{1}}-\frac{\bar{O}_{1}}{r_{1} v_{1}^{*}} ; \bar{I}_{2}=\frac{\bar{O}_{1}}{r_{1} v_{1}^{*}}-\frac{\bar{O}_{2}}{r_{2} u_{1}^{*}} \times \frac{K_{2}}{K_{1} a_{21}} ;
\end{gathered}
$$

The condition $\bar{O}_{i}>0$ means that species $i$ is over exploited and/or the mortality rate is high in the refuge. While the condition $\bar{I}_{i}>0$ is related to the case where species $i$ can invade when rare, $i \in\{1,2\}$. It is obvious that if species is over exploited and/or the mortality rate is high in the refuge then it gets extinct. For instance, if $\bar{O}_{1}>0$ and $\bar{O}_{2}<0$, it means that due to overfishing and/or to the high mortality rate in the refuge, the superior competitor is going extinct while the inferior competitor which is not overexploited will survive and tend to some carrying capacity. Now, we consider the case where both species are not over exploited. In this case, model 2 is the same as the classical LotkaVolterra competition model. The outcomes of model 1 are therefore the following: $(i)$ the superior competitor wins globally; $(i i)$ the inferior wins globally; $(i i i)$ species wins depending on initial conditions; or $(i v)$ the two species coexists. We are interested in the case where the inferior competitor wins globally- case $(i i)$. This case is valid if $\bar{O}_{1}, \bar{O}_{2}, \bar{I}_{1}<0$ and $\bar{I}_{2}>0$. These inequalities hold provided $K_{2}>K_{1}$ which is in agreement with the case of thiof and octopus. The environment carrying capacity of the inferior competitor -octopus $\left(K_{2}\right)$ is much large than the one of the superior competitor-thiof $\left(K_{1}\right)$. Figure 2 shows a phase portrait corresponding to the case. We compare, in Figure 3, the complete model (red line) and the aggregated model (blue dots). It can be seen that the two phase plane trajectories coincide for small values of $\varepsilon$. 


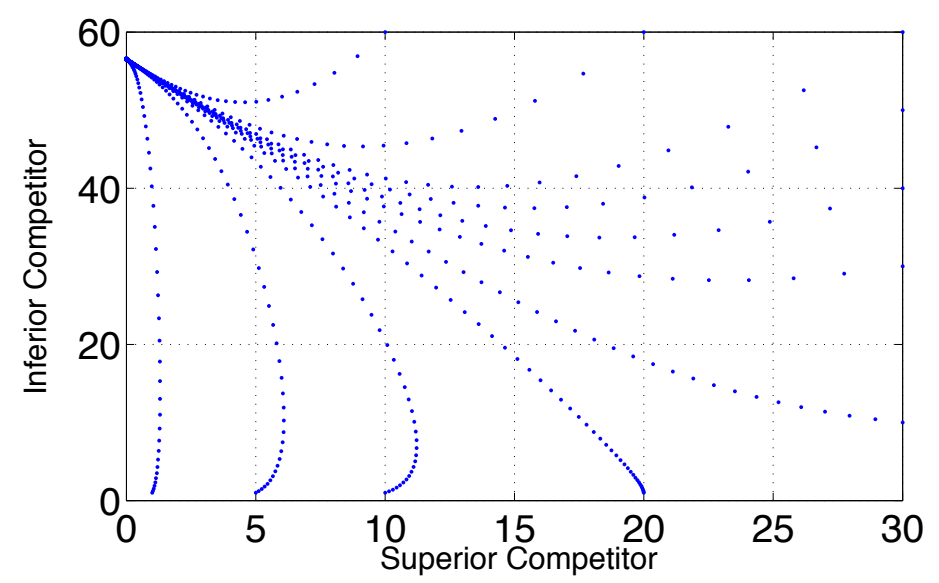

Fig. 2 Example with the inferior competitor wins globally in model 2. Parameters are chosen as follows $r_{1}=0.9 ; r_{2}=0.7 ; K_{1}=100 ; K_{2}=$ $100 ; a_{12}=0.8 ; a_{21}=2.2 ; q_{1}=0.6 ; q_{2}=0.3 ; E=0.9 ; d_{1}=0.2 ; d_{2}=0.4 ; k=5 ; \bar{k}=7 ; m=6 ; \bar{m}=0.2$.

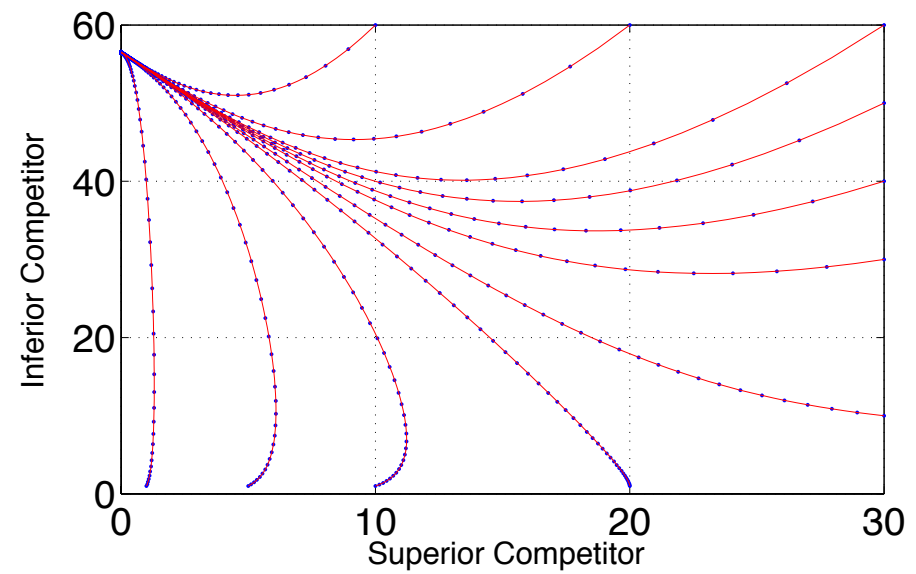

Fig. 3 Example with the inferior competitor wins globally in model 2: A comparison between the aggregated model (blue dots) and the complete model (red line). The parameters are the same as in Figure 2 except for $\varepsilon=0.01$.

2.3 Model 3: the case with refuge and density dependent migration

In this part, we consider a model which is similar to model 2 but with the density dependent migration case. Indeed, observations in Senegal have shown that during the benthic stage of his life (juvenile and adult stages), the octopus can stay hiding in its refuge during relatively long period $[12,13,19]$. It is may be to avoid contests with competitors and predators. On the contrary, the grouper may not be sensitive to octopus density [12,17]. As a consequence, in our model we assumed that the migration of octopus is grouper density dependent while the migrationof grouper is density 
independent. The model then reads as follows

$$
\left\{\begin{array}{l}
\frac{d n_{1 F}}{d \tau}=\left(k n_{1 R}-\bar{k} n_{1 F}\right)+\varepsilon r_{1} n_{1 F}\left(1-\frac{n_{1 F}}{K_{1}}-a_{12} \frac{n_{2 F}}{K_{1}}\right)-\varepsilon q_{1} n_{1 F} E \\
\frac{d n_{1 R}}{d \tau}=\left(\bar{k} n_{1 F}-k n_{1 R}\right)-\varepsilon d_{1} n_{1 R} \\
\frac{d n_{2 F}}{d \tau}=\left(m n_{2 R}-\left(\alpha n_{1 F}+\alpha_{0}\right) n_{2 F}\right)+\varepsilon r_{2} n_{2 F}\left(1-\frac{n_{2 F}}{K_{2}}-a_{21} \frac{n_{1 F}}{K_{2}}\right)-\varepsilon q_{2} n_{2 F} E \\
\frac{d n_{2 R}}{d \tau}=\left(\left(\alpha n_{1 F}+\alpha_{0}\right) n_{2 F}-m n_{2 R}\right)-\varepsilon d_{2} n_{2 R}
\end{array}\right.
$$

In equations (2.7), species 1 use density independent migration as in model 2. In addition, we assume that species 2 use density-dependent migration $\left(\alpha n_{1 F}+\alpha_{0}\right)$ from the fishing patch to the refuge. Here $\alpha$ is a parameter that represents the strength of density-dependence in migration, i.e. if there are too many $n_{1}$ individuals in the fishing patch then $n_{2}$ individuals are more likely to leave this patch to the refuge. In the case $\alpha=0$ then species 2 uses density-independent migration from the fishing patch to the refuge with the per capita emigration rate $\alpha_{0}$. The parameter $\varepsilon$ represents the ratio between two time scales $t=\varepsilon \tau$. Keeping in mind that we are still interested in the asymmetric competition. Therefore we use again the condition 2.2.

Again, we are going to use aggregation method to transform this model into a reduced system with two ordinary differential equations governing the dynamics of the global variables: the total density of species $1, n_{1}(t)=n_{1 F}(t)+$ $n_{1 R}(t)$, and the total density of species $2, n_{2}(t)=n_{2 F}(t)+n_{2 R}(t)$. Both are adequate candidates to global variables because they are constants of motion of the migration process, i.e., they keep constant at the fast time scale. If we forget the competitive interactions, global densities will not change but the distribution of each species between the two patches will evolve and tend towards certain equilibrium proportions. To calculate them let us suppose fixed values of $n_{1}$ and $n_{2}$ and find the equilibria of the fast part of system (2.7). We obtain for species 1

$$
n_{1 F}=\frac{k}{k+\bar{k}} n_{1}=v_{1}^{*} n_{1} \text { and } n_{1 R}=\frac{\bar{k}}{k+\bar{k}} n_{1}=v_{2}^{*} n_{1}
$$

and for species 2

$$
n_{2 F}=\frac{m}{H\left(n_{1}\right)} n_{2} \text { and } n_{2 R}=\frac{\alpha v_{1}^{*} n_{1}+\alpha_{0}}{H\left(n_{1}\right)} n_{2} \text { where } H\left(n_{1}\right)=\alpha v_{1}^{*} n_{1}+\alpha_{0}+m
$$


where constants $v_{1}^{*}$ and $v_{2}^{*}$ represent the fast density independent equilibrium proportions of species 1 on each patch while the functions $m / H\left(n_{1}\right)$ and $\left(\alpha v_{1}^{*} n_{1}+\alpha_{0}\right) / H\left(n_{1}\right)$ represent the fast species 1 density dependent equilibrium proportions of species 2 on each patch. It is immediate to prove that these equilibria are stable for fast dynamics.

Now, coming back to the complete model (2.7), we can write a system for the two global variables just by adding up the corresponding equations and substituting the former state variables by the fast equilibria (2.8) and (2.9) as follows:

$$
n_{1 F}=v_{1}^{*} n_{1}, n_{1 R}=v_{2}^{*} n_{1}, n_{2 F}=m n_{2} / H\left(n_{1}\right) \text { and } n_{2 R}=\left(\alpha v_{1}^{*} n_{1}+\alpha_{0}\right) n_{2} / H\left(n_{1}\right)
$$

Obtaining the following aggregated system at the slow time scale:

$$
\left\{\begin{array}{l}
\frac{d n_{1}}{d t}=n_{1}\left[\left(r_{1} v_{1}^{*}-q_{1} v_{1}^{*} E-d_{1} v_{2}^{*}\right)-\frac{r_{1} v_{1}^{* 2}}{K_{1}} n_{1}-\frac{r_{1} a_{12} v_{1}^{*} m}{K_{1} H\left(n_{1}\right)} n_{2}\right] \\
\frac{d n_{2}}{d t}=\frac{n_{2}}{H\left(n_{1}\right)}\left[\left(r_{2} m-q_{2} m E-d_{2}\left(\alpha v_{1}^{*} n_{1}+\alpha_{0}\right)\right)-\frac{r_{2} m^{2}}{K_{2} H\left(n_{1}\right)} n_{2}-\frac{r_{2}}{K_{2}} a_{21} m v_{1}^{*} n_{1}\right]
\end{array}\right.
$$

According to aggregation methods [2,3], we can study the dynamics of the complete system (2.7) by carrying out the study of the aggregated model (2.10). To avoid having a lot of parameters, we rewrite system (2.10) equations by using new parameters as follows:

$$
\left\{\begin{array}{l}
\frac{d n_{1}}{d t}=n_{1}\left[A-B n_{1}-\frac{C}{H\left(n_{1}\right)} n_{2}\right] \\
\frac{d n_{2}}{d t}=\frac{n_{2}}{H\left(n_{1}\right)}\left[M-N n_{1}-\frac{P}{H\left(n_{1}\right)} n_{2}\right]
\end{array}\right.
$$

where $A=r_{1} v_{1}^{*}-q_{1} v_{1}^{*} E-d_{1} v_{2}^{*} ; B=r_{1}\left(v_{1}^{*}\right)^{2} / K_{1} ; C=r_{1} a_{12} v_{1}^{*} m / K_{1} ; M=r_{2} m-q_{2} m E-d_{2} \alpha_{0} ; N=$ $d_{2} \alpha v_{1}^{*}+r_{2} a_{21} m v_{1}^{*} / K_{2} ; P=r_{2} m^{2} / K_{2}$.

$A$ and $M$ can be considered as the global growth rates for both species. Indeed, if one sets $n_{2}=0$ in the first equaion (2.11), species 1 grows according to a logistic growth with a global growth rate given by $A$. Similarly, if one sets $n_{1}=0$ in the second equation (2.11), species 2 also grows logistically with a global growth rate given by $M$. Those growth rates take into account the natural growth rate and the mortality due to fishing and to the mortality in the refuge.

\section{Denoting}

$$
\widetilde{O}_{1}=-A ; \widetilde{O}_{2}=-M ; \widetilde{I}_{1}=P A-M C ; \widetilde{I}_{2}=M B-N A
$$

The condition $\widetilde{O}_{i}>0$ means that species $i$ is over exploited and/or the mortality rate is high in the refuge. While the condition $\widetilde{I}_{i}>0$ is related to the case where species $i$ can invade when rare, $i \in\{1,2\}$. It is obvious that if species is over exploited and/or the mortality rate is high in the refuge then it gets extinct. For instance, if $\widetilde{O}_{1}>0$ and $\widetilde{O}_{2}<0$, 
it means that due to overfishing and/or to the high mortality rate in the refuge, the superior competitor is going extinct while the inferior competitor which is not overexploited will survive and tend to some carrying capacity. Now, we consider the case where both species are not over exploited. A full analysis of model 3 is given in the appendix. The outcomes of model 3 are the following: $(i)$ the superior competitor wins globally; $(i i)$ the inferior wins globally; $(i i i)$ species wins depending on initial conditions; or $(i v)$ the two species coexists. We are interested in the case where the inferior competitor wins globally- case $(i i)$. This case is valid if $\widetilde{O}_{1}, \widetilde{O}_{2}, \widetilde{I}_{1}<0$ and $\widetilde{I}_{2}>0$. Figure 4 shows a phase portrait corresponding to the case. We also compare, in Figure 5, the complete model (red line) and the aggregated model (blue dots). It can be seen that the two phase plane trajectories coincide for small values of $\varepsilon$.

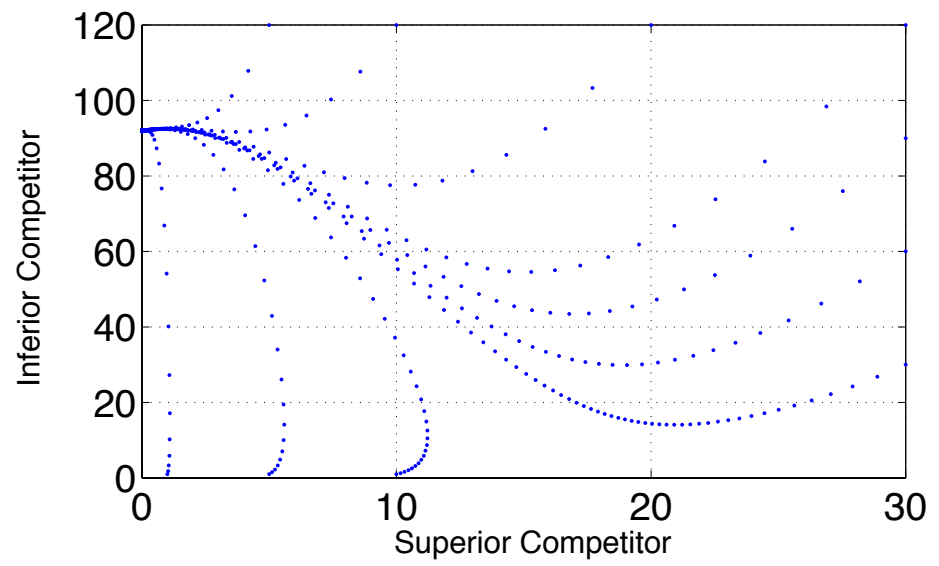

Fig. 4 Example with the inferior competitor wins globally in model 3. Parameters are chosen as follows $r_{1}=0.9 ; r_{2}=1.3 ; K_{1}=100 ; K_{2}=$ $100 ; a_{12}=0.8 ; a_{21}=2.2 ; q_{1}=0.6 ; q_{2}=0.3 ; E=0.9 ; d_{1}=0.2 ; d_{2}=0.4 ; k=5 ; \bar{k}=7 ; m=6 ; \alpha=1 ; \alpha_{0}=2$.

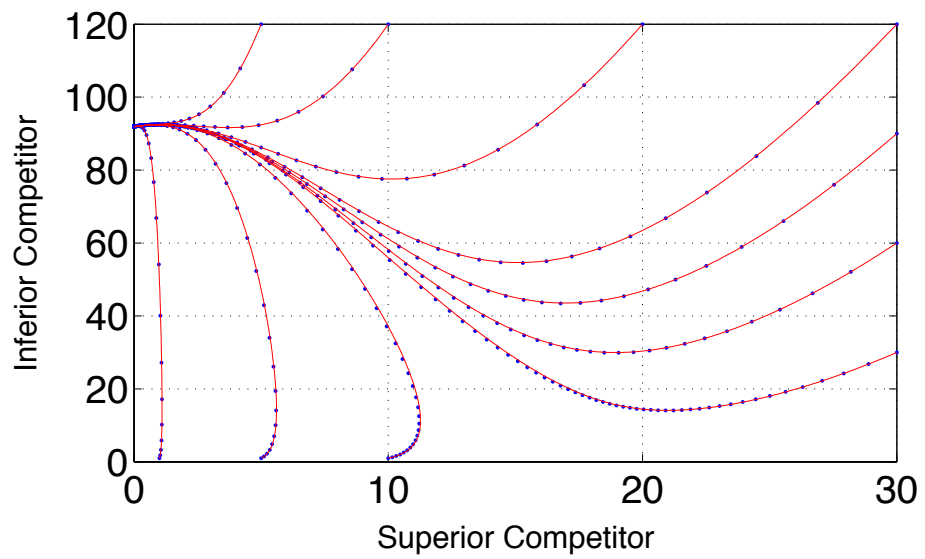

Fig. 5 Example with the inferior competitor wins globally in model 3: A comparison between the aggregated model (blue dots) and the complete model (red line). The parameters are the same as in Figure 4 except for $\varepsilon=0.01$. 


\section{Discussion and Conclusion}

\section{About the main result of the study}

Several situations or distinct hypothesis have been considered to describe (or simulate) the inter-specific competition between octopus and white grouper. This led to three versions of the model from the simplest to the more complicated one (model 1 to model 3). As the three models bring similar results, the discussion will focus on the analysis resulting from the model 2 that we consider as the most realistic one (considering what we can draw from the current knowledge of both species about the main mechanism in game in the targeted inter-species relationship). In addition, the model 2 represents an intermediate between model 1 and model 3 (a compromise in term of complexity). So in the following discussion, the generic term "model" will refer by default to the version 2 or model 2 otherwise the precision will be given (for other versions).

The most important result considering the ecological hypothesis we want explore about octopus explosion in Senegal and North western Africa, is the result emerging from the equilibria of the aggregated model and the local stability analysis. The model shows that in some conditions of fishing pressure the joint dynamics of both species can reach stable equilibrium in which the inferior competitor (octopus) is winner globally and the superior competitor (E. aenus) goes extincts. This interesting situation occurs when $\widetilde{O}_{1}>0$ and $\widetilde{O}_{2}<0$. In other words, the model predicts that extinction of the superior competitor will occur when:

- The fishing effort for the superior competitor (the thiof) is large enough to provoke a global negative growth rate $A$ or else $\widetilde{O}_{1}>0$ i.e. the superior competitor is over exploited.

- The fishing effort is large for the inferior competitor (the octopus) but its global growth rate $M$ remains positive or else $\widetilde{O}_{2}<0$ i.e. the inferior competitor is not over exploited.

It makes sense to think that this case could explain the observed situation for the thiof and the octopus along the Atlantic west African coast. Indeed, the natural growth rate of the octopus $r_{2}$ is large [18] which could lead to a positive global growth rate $M$ for this species even with fishing. On the contrary, the natural growth rate of the thiof $\left(r_{1}\right)$ is smaller in comparison and the fishing pressure on this species could be large enough to provoke a global negative growth rate $A$ for the thiof.

The same situation, i.e. extinction of the superior competitor, could also occur when the two global growth rates are positive $A>0$ and $M>0$. This means that in this last case, the fishing pressure is not large enough to provoke 
a global negative growth rate neither for the thiof or the octopus. In that case, two supplementary conditions must be verified, $\widetilde{I}_{1}<0$ and $\widetilde{I}_{2}>0$, which can be rewritten combining with the condition 2.2 as follows:

$-\widetilde{I}_{1}<0$ and $(2.2)$ are equivalent to

$$
\frac{K_{1}}{K_{2}} \times \frac{\left(1-\frac{q_{1} E}{r_{1}}-\frac{d_{1}}{r_{1}} \frac{\nu_{2}^{*}}{\nu_{1}^{*}}\right)}{\left(1-\frac{q_{2} E}{r_{2}}-\frac{q_{2}}{r_{2}} \frac{\mu_{2}^{*}}{\mu_{1}^{*}}\right)}<a_{12}<\frac{K_{1}}{K_{2}}
$$

where $\mu_{1}^{*}=m /\left(\alpha_{0}+m\right), \mu_{2}^{*}=1-\mu_{1}^{*}$.

- $\widetilde{I}_{2}>0$ and $(2.2)$ are equivalent to

$$
\frac{K_{2}}{K_{1}}<a_{21}<\frac{K_{2}}{K_{1}} \times\left[\frac{\left(1-\frac{q_{2} E}{r_{2}}-\frac{q_{2}}{r_{2}} \frac{\mu_{2}^{*}}{\mu_{1}^{*}}\right)}{\left(1-\frac{q_{1} E}{r_{1}}-\frac{d_{1}}{r_{1}} \frac{\nu_{2}^{*}}{\nu_{1}^{*}}\right)}-\frac{\alpha d_{2} K_{1}}{m r_{2}}\right]
$$

These inequalities provide lower and upper limits for competition parameters which could be difficult to check. However, due to the large number of parameters, an adequate choice of parameters could be made to check all inequalities.

Among the two previous cases leading to extinction of the superior competitor, we believe that the first case $(A<0$ and $M>0$ ) is a good candidate to explain observations that are made for thiof and octopus in Senegal and along the West Africa Atlantic coast.

Considering that the model has been constructed to integrate the general biological knowledge available on the two species and to simulate their potential interactions in the field, this result is a demonstration that the main hypothesis evoked by several authors $[8,11,20,28]$ to explain the explosion of octopus in a very plausible one.

Further and on a more general point of view our results gives a positive response to the question whether fishing pressure can invert the outcome of interspecific competition. This hypothesis is sometimes evoked when considering ecosystem effects of fishing (see for example NOAA (1998) and, in West Africa, [13, 14, 32, 33]) but to our knowledge only as a potential mechanism among others to interpret unexplained ecological changes in highly exploited ecosystems. This hypothesis is considered there at a very interpretative level without any attempt to demonstrate it on concrete specific examples. Here the demonstration is of course not complete, staying at a theoretical and analytical level (see discussion of this below). But this first step is nevertheless a very interesting result because of the wide range of consequence it brings in terms of fishery management.

\section{About some limitations of the present model and perspectives for future improvement}

Even if based on concrete species and their observed general dynamics, a pattern observed reproduced similarly along time in several area of the NW Africa (successively for North to South) during the extension of the octopus high 
density emergence and its subsequent exploitation by local fisheries, the model is still a theoretical one, not adjusted to observed data. A reason of this is the practical difficulty to have good estimates of octopus abundances (because of its high level of variability of the species at both the intra-annual and inter- annual temporal scale) and of white grouper abundances at the same place and in relatively long series with same step of time (annual steps for example). What is possible is to draw is thus the general scheme described in the introduction concerning the relative long term trends of the two species (based on observations combining scientific trawling, commercial catches and evolution of fishing strategies along last decades in the region). Anyway here this limitation is not a major problem as far as the adjustment is not needed regarding the main purpose of the paper: to build a generic and long term model, to explain the long term dynamics but not to simulate the short-term or middle-term joint dynamics of the two species. If one wants to go further in the description on the joint dynamic of both species and built a model to simulate this, at local and short term scale, this model will have to address or resolve the following issue:

a) The first one is the environmental based part of the abundance determinism of octopus which is kown to be very large [13,33]: a short term simulation model (adjusted to observed data) would have to take account the environmental variability that is essential to explain the observed short term abundance of octopus (due to annual and seasonal high variability of the recruitment depending of environmental condition of the year, coupled to the very short lifespan of the species: one year only [18].

b) The second issue concerns the difference in the speeds and natural variabilities of the two species dynamics: with a relatively stable fish species of several year lifespan (thiof) and a very unstable species of only one year lifespan (and half of this lifespan is represented by eggs development and pelagic larval stages, unobservable in the field and of very low individual biomass).

c) The third issue will be to build a model more complex regarding the fishing pressure. This model should include a variable (non constant) fishing pressure (and the eventually the mechanistic of the fishing pressure variation because the reality where fishing pressure is has also a dynamic and complex determinism).

Indeed in the reality for our bi-species system, in terms of fishing pressure as well as for environmental influence, we are not in stable external conditions and this is an issue to address in future modeling study aiming to simulate a concrete and short term dynamics.

\section{About some consequence in term of fisheries management}

The present study brings analytical argument on the fact that fishing pressure can invert the outcomes of interspecific competition. As previously highlighted this is the major ecological result considering potential fishing effects. But this result has also practical consequences to take into account when considering ecosystem based fishery management in general and specially in the case of emerging or new resources in multi-target fishery context. The stock 
assessment and the related scientific advice to provide for this kind of resource case cannot be based only on classical monospecific approach.

In the case of the West Africa regional emergence of octopus high concentrations and exploitation, we have to reconsider the way to assess the octopus resources in link with the other demersal resources and in particular the related MSY (maximal sustanaible yields) estimations on these resources.

A management based on collection of cumulated mono-specifically based MSY, leads to unrealistic fisheries objectives, because based on a unrealistic vision of the cumulated productivity of the area. This modeling reinforce the necessity to improve our ecological knowledge and the panel tools for fisheries assessment (like models and ecosystem indicators), in order to brings current fisheries stock-based management towards more integrative and ecosystem based fisheries management.

Acknowledgements This work was done while Doanh Nguyen-Ngoc was visiting at the Vietnam Institute for Advanced Study in Mathematics (VIASM). The author would like to thank to VIASM for financial support and hospitality. Didier Jouffre was assigned by IRD (Institut de Recherche pour le Développement) at the University Cheikh Anta Diop of Dakar (UCAD) to occupy a position of Deputy Director of the Laboratoire de Biologie et d'Ecologie de Poissons en Afrique de l'Ouest (LABEP-AO), a joint Laboratory between IRD (MARBEC Research Unit) and UCAD (Institut Fondamental d'Afrique Noire Cheikh Anta Diop). The author would like to thank to IRD for support and UCAD-IFAN for support and hospitality. This research is funded by Vietnam National Foundation for Science and Technology Development (NAFOSTED) under a grant. This research is a Labep-AO contribution to the AWA project (www.awa-project.org) co-funded by the German (BMBF) and French (MAE) Ministries of Cooperation and Foreign Affairs.

\section{References}

1. Amaratunga, 1987: Population Biology. In : Cephalopod Life Cycles, Volume II : Comparative Reviews. P.R. Boyle (Ed). Academic Press (London): 239-252.

2. Auger P, Bravo de la Parra R, Poggicale JC, Sanchez E, Nguyen Huu T, 2008a: Aggregation of variables and applications to population dynamics, in Magal P, Ruan S (eds.), Structured Population Models in Biology and Epidemiology, Lecture Notes in Mathematics, Vol. 1936, Mathematical Biosciences Subseries, Springer, Berlin, pp. 209-263.

3. Auger P, Bravo de la Parra R, Poggiale JC, Sanchez E, Sanz L, 2008b: Aggregation methods in dynamical systems variables and applications in population and community dynamics, Phys Life Rev 5:79105.

4. Arístegui J., Barton E. D., Álvarez-Salgado X.A., Santos A M. P., Figueiras F.G., Kifani S., Hernández-León S., Mason E., Machú M., Demarcq H.,2009: Sub-regional ecosystem variability in the Canary Current upwelling, Progress in Oceanography, Volume 83, Issues 14, December 2009, Pages 33-48, ISSN 0079-6611, http://dx.doi.org/10.1016/j.pocean.2009.07.031.

5. Balguerías E., M. E. Quintero, and C. L. Hernández-Gonzáez, 2000: The origin of the Saharan Bank cephalopod fishery ICES J. Mar. Sci. 57 (1): 15-23 doi:10.1006/jmsc. 1999.0572

6. Bravo de Laguna, 1982: Distribution and abundance of demersal resources of the CINECA region. Rapports et Procès-verbaux des Réunions du Conseil International pour l'Exploration de la Mer, 180: 432-446. 
7. Bravo de Laguna, J. et Balguerias, E., 1993: La pesqueria sahariana de cefalopodos : una breve revision : Bol Inst. Esp. Oceanogr. 9 (1): $203-213$.

8. Caddy, J.F. (Ed.), 1983: Advances in assessment of world cephalopod resources. FAO Fish. Tech. Pap., 231: 1-452.

9. Caddy, J., and Rodhouse, P. G. 1998: Comparison of recent trends in cephalopod and groundfish landings: an indicator of widespread ecological change in global fisheries. Reviews in Fish Biology and Fisheries, 8: 431-444.

10. Caverivière A., 1990: Étude de la pêche du poulpe (Octopus vulgaris) dans les eaux côtières de la Gambie et du Sénégal. L'explosion démographique de l'éte 1986. Centre Rech. Oceanogr. Dakar Thiaroye, Doc. scient, 116 : 1-42.

11. Caverivière A., 1994: Le poulpe (Octopus vulgaris) au Sénégal : une nouvelle ressource. in. Barry-Gérard M., Diouf T. et Fonteneau A. (eds). L'évaluation des ressources exploitables parla pêche artisanale sénégalaise. Paris, Orstom éditions, coll. Colloques et séminaires, Tome 2 : 245-256.

12. Caverivière A., 1997: Note sur l'observation de terriers creusés dans le sable et occupés par des juvéniles d'Octopus vulgaris. in: Rapport du groupe de travail ad hoc sur les cphalopodes. FAO, COPACE/PACE SERIES/97/63, $98 \mathrm{p}$.

13. Caverivière A., Diallo M., Domain F., Jouffre D., 2000: Répartition côtière du poulpe Octopus vulgaris sur la Petite Côte du Sénégal et son exploitation par la pêche artisanale. In Gascuel D., Chavance P. Bez, N and Biseau A. (eds), "Les Espaces de l'Halieutique", 4ème forum halieumétrique, Editions IRD, Paris, coll. Colloques et Séminaires, 269-283.

14. Chavance P, Ba M, Gascuel D, Vakily M and Pauly D, 2004: Pêcheries maritimes, écosystèmes et sociétés en Afrique de l'Ouest : un demisiècle de changement [Marine fisheries, ecosystems, and societies in West Africa: Half a century of change]. Actes du symposium international, Dakar-Sénégal, 24-28 Juin 2002. Office des publications officielles des communautés Européennes, XXXVI, collection des rapports de recherche halieutique ACP-UE 15, Brussels. $532 \mathrm{p}$.

15. Demarcq H., 2009: Trends in primary production, sea surface temperature and wind in upwelling systems (1998-2007). Progress in Oceanography, 83 (1-4), p. 376-385. ISSN 0079-6611

16. Diallo M, Jouffre D., Caverivière A., Thiam M., 2012. The demographic explosion of Octopus vulgaris in Senegal during the 1999 summer. Bulletin of Marine Science. Vol. 71, No. 2: pp. 1063-1065.

17. Diatta, Y., Bou-Ain, A., Clotilde-Ba, F. and Capapé, C. 2003: Diet of four serranid species from the Senegalese coast (eastern tropical Atlantic). Acta Adriatica 44(2): 175-182.

18. Domain F, Jouffre D., Caverivière A., 2000: Growth of Octopus vulgaris from tagging in Senegalese waters. J. Mar. Biol. Ass. U.K., 80 (4): 699-706

19. Heemstra, P.C. and J.E. Randall, 1993: FAO Species Catalogue. Vol. 16. Groupers of the world (family Serranidae, subfamily Epinephelinae). An annotated and illustrated catalogue of the grouper, rockcod, hind, coral grouper and lyretail species known to date. Rome: FAO. FAO Fish. Synop. 125(16): $382 \mathrm{p}$.

20. Jouffre D., 1998: Octopus vulgaris as a component of the benthic fauna of the NW African coast: A note on an investigation of species community organisation using multifactorial analysis. S. Afr. J. mar. Sci: 20: 93-100.

21. Jouffre D., Inejih C., Simier M., 2000: Cycle biologique du poulpe (Octopus vulgaris) au large du Cap-Blanc (Mauritanie). 4ème forum halieumétrique, ”Les Espaces de l'Halieutique”. Paris, IRD, coll. Colloques et Séminaires, 243-267.

22. Laurans, M., Barry, M. and Gascuel, D., 2003: Revue des connaisances sur la biologie du thiof (Epinephelus aeneus) et diagnostic de l'etat du stock au Senegal. In: D. Gascuel, M.D. Barry, M. Laurans and A. Sidibe (eds.), In: Evaluation des stocks demersaux en Afrique du nord-ouest. Travaux du Groupe ”Analyses monospecifiques” du projet SIAP. COPACE/PACE Series 03/65: pp. 5-70.

23. Meissa B., Gascuel D. and Rivot E., 2013: Assessing stocks in data-poor African fisheries: a case study on the white grouper Epinephelus aeneus of Mauritania. African Journal of Marine Science 35 (2): 253-267.

24. Murray, J.D., 2003: Mathematical Biology. I. An Introduction. Springer, New York. 
25. Ndiaye, W., Thiaw M., Diouf K., Ndiaye P., Thiaw OT and Panfili J., 2013: Changes in population structure of the white grouper Epinephelus aeneus as a result of long-term overexploitation in Senegalese waters. African Journal of Marine Science, 35.4: 465-472.

26. Nguyen-Ngoc D., Nguyen-Huu T., Auger P., 2012: Effects of Refuges and Density Dependent Dispersal on Interspecific Competition Dynamics. International Journal of Bifurcation and Chaos, 22(2): 1250029.

27. Stephen K. Brown, Peter J. Auster, Liz Lauck, and Michael Coyne, 1998: National Oceanic and Atmospheric Administration (NOAA). (online).”Ecological Effects of Fishing". NOAA's State of the Coast Report. Silver Spring

28. Pereiro, J.A., et Bravo de Laguna, J., 1981: Dynamique des populations et évaluation des stocks de poulpes de l'Atlantique Centre-Est. FAO, COPACE/PACE SERIES 80/18: 57pp.

29. Rathjen, W. F., et Voss, G. L., 1987: The cephalopod fisheries : a review. In: Cephalopod Life Cycles, Comparative Reviews, P.R. Boyle (Ed), Academic Press (London), Vol. 2: 253-275.

30. Roy C., 1991: Les upwellings : le cadre physique des pêcheries côtières ouest-africaines In : Pêcheries Ouest-africaines, variablité, instablité et changement, Cury P. et Roy C. (Eds), O.R.S.T.O.M. Editions (Paris) : 38-66.

31. Thiao D., C. Chaboud, A. Samba, F. Laloe, P. Cury, 2012: Economic dimension of the collapse of the false cod Epinephelus aeneus in a context of ineffective management of the small-scale fisheries in Senegal Afr. J. Mar. Sci., 34: pp. 305311.

32. Thiaw M, Gascuel M., Jouffre D. and O. T. Thiaw, 2009: A surplus production model including environmental effects: Application to the Senegalese white shrimp stocks. Progress in Ocenagraphy, 83: 351-360.

33. Thiaw M, Gascuel M., Thiao D., Thiaw O. T. and Jouffre D. 2011: Analyzing environmental and fishing effects on a short-lived species stock: the dynamics of octopus population, Octopus vulgaris, in the Senegalese waters. African Journal of Marine Science, 33 (2): 209-222.

\section{A Equilibria and local stability analysis of aggregated model}

\section{A.1 Rewrite model}

To simplify, we denote by $f\left(n_{1}, n_{2}\right)$ the function $A-B n_{1}-\frac{C}{H\left(n_{1}\right)} n_{2}$ and by $g\left(n_{1}, n_{2}\right)$ the function $M-N n_{1}-\frac{P}{H\left(n_{1}\right)} n_{2}$. The model is therefore written as follows:

$$
\left\{\begin{array}{l}
\frac{d n_{1}}{d t}=n_{1} f\left(n_{1}, n_{2}\right) \\
\frac{d n_{2}}{d t}=\frac{n_{2}}{H\left(n_{1}\right)} g\left(n_{1}, n_{2}\right)
\end{array}\right.
$$

\section{A.2 Jacobian matrix}

$$
J\left(n_{1}, n_{2}\right)=\left(\begin{array}{cc}
f+n_{1} f_{n_{1}}^{\prime} & n_{1} f_{n_{2}}^{\prime} \\
\frac{n_{2}}{H\left(n_{1}\right)} g_{n_{1}}^{\prime}-\frac{n_{2} g \alpha v_{1}^{*}}{H^{2}\left(n_{1}\right)} & \frac{g}{H\left(n_{1}\right)}+\frac{n_{2}}{H\left(n_{1}\right)} g_{n_{2}}^{\prime}
\end{array}\right)
$$




\section{A.3 Equilibria and stability}

- At $(0,0)$ :

$$
J(0,0)=\left(\begin{array}{cc}
A & 0 \\
0 & \frac{M}{\alpha_{0}+m}
\end{array}\right)
$$

The matrix has two eigenvalues $A$ and $M /\left(\alpha_{0}+m\right)$. Therefore, $(0,0)$ stable if and only if $M, A<0$.

- At $\left(\frac{A}{B}, 0\right)$ (the condition for its existence is that $A>0$ )

$$
J\left(\frac{A}{B}, 0\right)=\left(\begin{array}{c}
-A-\frac{A C}{B H\left(\frac{A}{B}\right)} \\
0 \frac{M-N \frac{A}{B}}{\alpha_{0}+m}
\end{array}\right)
$$

The matrix has two eigenvalues: $\lambda_{1}=-A<0$ and $\lambda_{2}=(M B-N A) /\left(B\left(\alpha_{0}+m\right)\right)$. Thus, $(A / B, 0)$ is stable if and only if $M B-N A<$ 0

- At $(0, M H(0) / P)$ (the condition for its existence is that $M>0$ )

$$
J(0, M H(0) / P)=\left(\begin{array}{cc}
\frac{P A-M C}{P} & 0 \\
\frac{M H(0) / P}{H(0)} g_{n_{1}}^{\prime}-\frac{M H(0) / P g \alpha v_{1}^{*}}{H^{2}(0)} & -\frac{M}{H(0)}
\end{array}\right)
$$

The matrix has two eigenvalues: $\lambda_{1}=-M / H(0)<0$ and $\lambda_{2}=(P A-M C) / P$. Thus, $(0, M H(0) / P)$ is stable if and only if $P A-$ $M C<0$.

- At $\left(n_{1}^{*}, n_{2}^{*}\right)$ where $n_{1}^{*}=(P A-M C) /(P B-N C), n_{2}^{*}=\left(A-B n_{1}^{*}\right) H\left(n_{1}^{*}\right) / C$ (the condition for its existence is that $0<(P A-$ $M C) /(P B-N C)<A / B)$. The Jacobian matrix reads as follows:

$$
J\left(n_{1}^{*}, n_{2}^{*}\right)=\left(\begin{array}{cc}
n_{1}^{*} f_{n_{1}^{*}}^{\prime} & n_{1}^{*} f_{n_{2}^{*}}^{\prime} \\
\frac{n_{2}^{*} g_{n_{1}^{*}}^{\prime}}{H\left(n_{1}^{*}\right)} & \frac{n_{2}^{*} g_{n_{2}^{*}}^{\prime}}{H\left(n_{1}^{*}\right)}
\end{array}\right)
$$

A straightforward calculation leads to the following two possibilities (see figure 6 for more information). The first one, corresponding to conditions $P A-M C>0$ and $M B-N A>0$, is the case where $\left(n_{1}^{*}, n_{2}^{*}\right)$ is a stable point. The second one, corresponding to conditions $P A-M C<0$ and $M B-N A<0$, is the case where $\left(n_{1}^{*}, n_{2}^{*}\right)$ is a saddle point. 


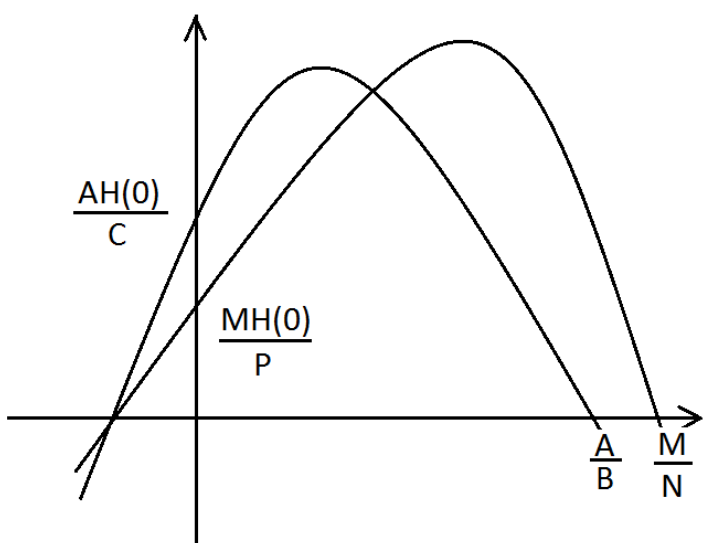

(a)

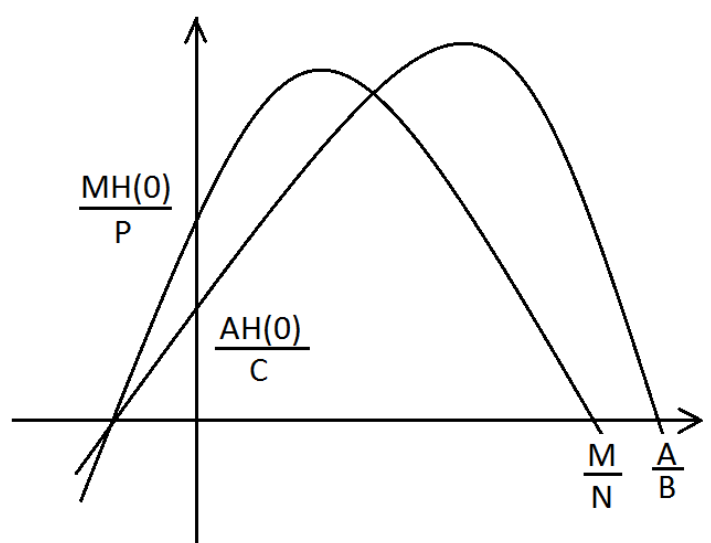

(b)

Fig. 6 Two cases where there exists a strictly positive equilibrium. (a) is related to the case where it is stable, (b) is related to the case where it is saddle.

Thuy Nguyen-Phuong

${ }^{1}$ School of Applied Mathematics and Informatics, Hanoi University of Science and Technology,

No1 Dai Co Viet street, Hai Ba Trung District, Hanoi, Vietnam.

Email: thuynpsami@gmail.com

Doanh Nguyen-Ngoc

${ }^{1}$ School of Applied Mathematics and Informatics, Hanoi University of Science and Technology,

No1 Dai Co Viet street, Hai Ba Trung District, Hanoi, Vietnam.

Email: doanhbondy@gmail.com

Pierre Auger

${ }^{2}$ UMI UMMISCO 209, IRD, 32 avenue Henri Varagnat, 93143 Bondy Cedex, France.

UPMC Univ Paris 06, UMI 209, UMMISCO, F-75005 Paris, France

${ }^{3}$ IRD UMI UMMISCO-Senegal, UCAD, Dakar, Senegal.

Email: pierre.auger@ird.fr

Sidy Ly

${ }^{3}$ IRD UMI UMMISCO-Senegal, UCAD, Dakar, Senegal.

Email: lysidyly@gmail.com

Didier Jouffre

${ }^{4}$ Institut de Recherche pour le Développement (IRD), UMR 248 MARBEC, LABEP-AO (IRD-IFAN), BP 1386, Dakar, Senegal Email: didier.jouffre@ird.fr 